\title{
Nutritive and Non-Nutritive Sucking Habits - Effect on the Developing Oro-Facial Complex; A Review
}

\section{Jyoti S* and Pavanalakshmi GP}

Department of Pedodontics and Preventive Dentistry, Vydehi Institute of Dental Sciences, EPIP area, White field, Bangalore, India

\begin{abstract}
Children have unique dental needs. During developmental period, the children go through various phases i.e., from no teeth, to primary teeth, to loosing teeth, to permanent teeth, which occur in about the first 12-14 years. If this routine goes without any disturbance, the child enters the adulthood with a strong and healthy dentition and oral structures. If there is any disturbance, either physical or psychological or both, it will result in mal development and malocclusion.

The development and maturation of normal oropharyngeal function plays an important role in craniofacial growth and occlusal physiology. Any muscular imbalance caused by intrinsic or extrinsic pressure will show their effect on the growing bone which will result in malocclusion. One of the important factors resulting in malocclusion is oral habit practiced by a child.
\end{abstract}

Having an oral habit is not a tragic situation, but needs to be stopped at the appropriate time with an appropriate method to get a good long-term result.

Keywords: Nutritive sucking habit; Non-nutritive sucking habit; Orofacial complex

\section{Introduction}

Suckling is a reflex occurring in the oral stage of development and disappears during normal growth between the ages 1 and $31 / 2$ years $[1,2]$. It is the first coordinated muscular activity of the infant, which helps in breast-feeding. In the newborn, i.e., gum pad stage of development there is open bite, and the tongue is relatively large and is positioned forward during normal suckling. The tip of the tongue actually takes part in the anterior lip seal. This is normal for infants and is termed as infantile or visceral swallowing. With eruption of incisors at approximately six months of age, the tongue position starts to retract from the anterior gum pads, shifting to adult or somatic swallowing.

\section{Types of Sucking}

- There are two forms of sucking [1].

- Nutritive form:

- It provides essential nutrients

- Breast feeding

- Bottle feeding

- Non nutritive form: Nonnutritive sucking is the earliest sucking habit adopted by infants in response to frustrations and to satisfy their urge and need for contact [2].

- Ensures a feeling of well feeling, warmth and sense of security

- Pacifier sucking

- Digit sucking

\section{Nutritive Sucking}

\section{Breast feeding}

It is a nutritive sucking habit which promotes a better orofacial development. There is a rapid mandibular protrusion movement in the breast fed baby than in the bottle fed baby. In certain infants the infantile swallowing persists well beyond 6 months of age. According to Graber et al. [3] it appears that several factors account for the persistence of infantile swallowing patterns. Separately or in combination they may be due to finger sucking, bottle feeding and mouth breathing. Labbok and Hendershot noted that there is a strong indication that breast feeding, especially if prolonged does protect against malocclusion. They concluded that, oral facial development might be one health issue on which breastfeeding may have measurable impact [4].

\section{Bottle feeding}

The effects of bottle feeding on the dentofacial development vary according to the type of the nipples used. Some Nipples are physiologically designed and referred to as "orthodontics".

With the physiologically designed nipple there is forward movement of the tongue under the flat surface of the nipple that draws it backward and upward against the hard palate of the infant. Consequently the child has to work and exercise the lower jaw. The posterior part of the tongue then awaits the milk and pushes it down into the esophageal area. Thus milk flows due to the peristaltic like action of the tongue and cheeks, instead of being squirted in to the throat that occurs when an inadequate nipple is used. The physiologically designed nipples seems better adapted to the anatomy and physiology of sucking.

\section{Non Nutritive Sucking}

Non-nutritive sucking is probably the earliest sucking habit adopted by infants in response to frustration and to satisfy their urge and need for contact. Many studies have been conducted to know the effect of nonnutritive sucking habits on the developing occlusion.

Degan and Puppin-Rontani [5] in their study found a linear relationship between breast feeding and pacifier use, demonstrated that

*Corresponding author: Dr. Sapna Jyoti, Associate Professor, Vydehi Institute of Dental Sciences, EPIP area, White field, Bangalore-560066, India, Tel: +919900408537; E-mail: drsapnapedo@gmail.com

Received December 17, 2013; Accepted Janaury 28, 2014; Published January 30, 2014

Citation: Jyoti S, Pavanalakshmi GP (2014) Nutritive and Non-Nutritive Sucking Habits - Effect on the Developing Oro-Facial Complex; A Review. Dentistry 4: 203. doi:10.4172/2161-1122.1000203

Copyright: (C) 2014 Jyoti S, et al. This is an open-access article distributed unde the terms of the Creative Commons Attribution License, which permits unrestricted use, distribution, and reproduction in any medium, provided the original author and source are credited. 
more the child was breast fed, the less the pacifier was used. Another study conducted by Viggiano et al. [6] concluded that non-nutritive sucking activity rather than the type of feeding in the first months of life is the main risk factor for the development of altered occlusion and open bite in deciduous dentition. Children with non-nutritive sucking activity and being bottle fed had more than double the risk of posterior cross bite. Breast feeding seems to have a protective effect on development of posterior cross bite in deciduous dentition.

Warren et al. [7] conducted a study to known about the extent to which nonnutritive sucking habits contribute to malocclusion in the mixed dentition. The purpose of this study was to report on the relationship between certain occlusal traits in the mixed dentition and longitudinal sucking behaviors. Overall, anterior open bite and posterior crossbite was associated with habits of 36 months or more. Sustained pacifier habits, including those of 24 to 47 months, were associated with anterior open bite and Class II molar relationships, while digit habits were associated with anterior open bite when sustained for 60 months or longer.

A study was conducted to determine prospectively the duration of nonnutritive sucking behaviors of children between 1 and 8 years of age and the effect of persistent habits on selected occlusal characteristics in the late deciduous dentition. There was a significant decrease in the incidence of pacifier habits between 1 and 5 years of age, from $40 \%$ to $1 \%$. There was a significant decrease in the incidence of digit habits between 1 and 4 years of age, from $31 \%$ to $12 \%$. Between 7 and 8 years of age, there was an additional significant decrease in the incidence of digit habits, but $4 \%$ of the children were, to various extents, still sucking fingers. Children who had pacifier or digit habits lasting less than 12 months did not have significantly different occlusal characteristics than children who were breast-fed for 6 to 12 months. Prolonged pacifier and digit habits caused significant changes in the occlusal characteristics in the late deciduous dentition, and the effects of pacifier habits were different from those of digit sucking. They concluded that the developing occlusion should be observed in the deciduous dentition in children with prolonged digit or pacifier habits. The transverse occlusal relationship, particularly in pacifier-sucking children, should be evaluated between 2 and 3 years of age. If there are interfering contacts of the deciduous canines, the parents should be instructed to reduce pacifier-sucking time, and appropriate treatment should be rendered [8].

\section{Pacifier Sucking [9]}

Children who do not have access to unrestricted breast feeding or who are bottle fed may satisfy their instinctive sucking urge with a pacifier. It has been reported that children who use a pacifier are less likely to develop a digit habit. It may also be that a pacifier is easier for the child to give up and that use ends at a younger age.

If a pacifier is being used, it is important to make parents aware of the following

- Anatomic pacifiers are more preferred

- Should be sturdy one-piece construction

- Should have an easily grasped handle

- Should have mouth guard of adequate diameter and with ventilating holes

- Should not have any detachable strings and ribbons

- Should never be tied around the child's neck or affixed with any material capable of becoming wrapped around the neck.
- Should be kept clean

- Should never dipped in sugar, honey or other sweetened material to encourage sucking.

\section{Thumb Sucking}

It is normal for infants to suck their fingers or thumb. However, there is conflicting opinion as to the age at which digit sucking becomes a symptom of an emotional disturbance with being deleterious to the growth and development to the teeth and facial bones.

This non-nutritive sucking habit is considered to be the most prevalent of oral habits with the reported incidence that ranges from $13 \%$ to almost $100 \%$ at some time during infancy. The prevalence of digit habits decreases with age and most children give up this activity by 3.5 to 4 yrs of age. On occasion, individuals may continue to exhibit a digit habit throughout childhood and may even extend this behavior into the adult years. The continuation of oral habits has been attributed to boredom, stress, hunger, hyperactivity, sadness, and pleasure etc.

Gellian reported a $45 \%$ prevalence of digit sucking in 3-4.5 year olds, $13.6 \%$ in $6 \mathrm{yr}$ old and $5.9 \%$ in children of $7-11$ year and $16 \%$ and $4.5 \%$ prevalence is reported for children between 3 and 12 year of age. Nanda and others have found the habit to be significantly more common among females. If the digit sucking continues beyond the age 6-7 months, it is difficult to break until the child is 4 or 5 years old [10].

In another study conducted by Luzzi et al. [11] in 2011 there was a higher prevalence rate of children with a posterior cross bite who had sucked the pacifier and the children with increased overjet who had sucked their finger.

A study was conducted by Franco Varas V, Gorritxo Gil B showed a significant increase in malocclusion in the primary dentition of children who prolonged the habit of pacifier sucking. If this habit was abondened early, anterior open bites improved, while posterior cross bites clutch remained or ever got worse. On-nutritive sucking habits can cause undesirable effects on the dentition and even affect the bone of the anterior part of the mandible. Continuous presence of thumb or finger in the oral cavity can exert sufficient pressure to deform the maxillary arch or palate or both. There is a strong agreement that the digit sucking habits that persist while permanent teeth erupt can have detrimental effects on the dentofacial development. For the first 3-4 years of life, the damage to the occlusion is confined largely to the anterior segment. These damages are usually temporary, provided the sucking habits are discontinued before 6 year of age. In case the habit is discontinued after 6 year of age, such children invariably have malocclusion at 12 years of age [12].

The effect on the development of the dentofacial structures with the persistence of these habits depend on the:

- The frequency of the habit

- Duration of the habit

- Intensity of the sucking

- Relationship of the dental arches

- Childs physical health

- Direction and nature of force excreted by the digit.

\section{Management}

The treatment for digit sucking should deal directly with the child. The first ingredient needed to help stop the habit is the child's desire to 
stop. Once it is achieved, the dentist can proceed with different levels of treatment modalities depending on the severity of the condition. If the child is not interested in changing the habit, then it is important to direct the parent's attention to other positive interactions with their child and away from concern about the habit.

If digit sucking causes malocclusion and the habit is discontinued between the ages of 4-5 yrs, self-correction of malocclusion can be expected. Self-correction also depends on the severity of the malocclusion, anatomic variation in the perioral soft tissue and the presence of other habits such as tongue thrusting, mouth breathing and lip habits. When digit sucking continues after 6 years or into the mixed dentition, there is an increased probability that the habit induced malocclusion will not self correct.

The levels of treatment possibilities that are usually considered are

\section{- Age appropriate explanations to the child}

Clinical photography's and the explanations with the consideration of physical appearance and social acceptance may be sufficient for the child to decide to give up the behavior

\section{- Positive reinforcement}

For a child who is ready to quit the habit and just needs a reason to stop, positive reinforcement may be helpful tool. Posting a calender on the refrigerator or in some other noticeable location and keeping a track of habit free days can give the child a sense of pride. Rewards for the progress in diminishing should include praise but may also include something special that is agreed on between parent and child.

\section{- Digital reminders:}

Placement of a reminder on the digit involved in the habit helps the child to immediately become conscious of the habit as soon as the child performs it and hence remove the digit from the mouth.

\section{o Chemical means}

Hot tasting, bitter preparations or distasteful agents can be applied on the digit involved in the habit. These agents help the children to keep the digit out of the mouth. These preparations are effective in only limited number of children and only when the habit is not firmly entrenched.

\section{o Mechanical means}

Simple devices for controlling thumb or finger sucking is the application of adhesive tape to the thumb or finger. This adhesive tape will remind the child not to suck.

\section{- Appliance therapy}

For more deeply ingrained habits or for parents who are more reluctant to let go of the habit, an intraoral appliance serves as the most effective deterrent. These appliances are not meant to be punitive. When the appliance is placed there is a clear message to the child and parent that the clinician is trying to help the child get past these deleterious behaviors and promote normal growth. The appliance can be removable or fixed. The various appliances used to break the habit and correct the malocclusions are:

$$
\begin{array}{ll}
\text { o } & \text { Palatal crib } \\
\text { o } & \text { Rakes } \\
\text { o } & \text { Oral screen } \\
\text { o } & \text { Lingual arch appliance }
\end{array}
$$

o Blue grass appliance

o Soldered W arch

o Quad helix

Prevention

- Health professionals should consider the teaching of the subject of oral habits as part of dental programs

- Specific recommendations must be addressed to parents on the child's sucking need and its role in oral muscular activity

- Breast feeding must be considered as an best method of feeding and prevention of malocclusion is one additional benefits of breast-feeding

- For bottle feeding always use of physiologically designed nipples should be preferred than conventional nipples.

- Prenatal dental education is necessary for the parents.

\section{Conclusion}

Oral habits in children usually initiate as normal reflex which may be pleasant or unpleasant. Most habits disappear when child reaches school. In rare instances habit is no longer a habit, but may be the result or the cause of physical or psychological problem. If these habits are practiced with more frequency, and for longer duration, the muscle imbalance of the growing dental structures will cause malocclusion, facial mal development and speech.

Attempts must be made to pin point the cause and treat it to break the habit. Habits, both good and bad are patterns of behavior which are actively learnt by the child. Teaching of good habits to children and elimination of bad one is one of the important skills for the parent to learn.

Parents should be educated about benefits of the exclusive breast feeding in the first 6 months of age on mixed dentition. The activity of non-nutritive sucking should be diagnosed in a timely manner in order to reduce the development of posterior cross bite, anterior open bite, and Class II molar relationship.

\section{References}

1. Grabber TM (1959) Thumb and Finger sucking. Am J Orthod 45: 259-264.

2. Massler M (1983) Oral Habits: Development and Management. J Pedod 27: 109-119.

3. Graber TM, Rakosi T, Petrovic AG (1985) Dentofacial orthopedics with functional appliances. CV Mosby, St. Louis.

4. Turgeon-O' Brein H, Lachapalle D, Gagnon PF, Larocque I, Maheu-Robert LF (1996) Nutritive and Non nutririve sucking habits: A review. ASDC J Dent Child 63: 321-327.

5. Degan VV, Puppin-Rontani RM (2004) Prevalence of pacifier sucking habits and successful methods to eliminate them- a preliminary study. J Dent Child 71: $148-151$.

6. Viggiano D, Fasano D, Monaco G, Strohmenger L (2004) Breast feeding, bottle feeding and non-nutritive sucking; Effects on occlusion in deciduous dentition. Arch Dis Child 89: 1121-1123.

7. Warren JJ, Slayton RL, Bishara SE, Levy SM, Yonezu T, et al. (2005) Effects of nonnutritive sucking habits on occlusal characteristics in the mixed dentition. Pediatr Dent 27: 445-50.

8. Bishara SE, Warren JJ, Broffitt B, Levy SM (2006) Changes in the prevalence of nonnutritive sucking patterns in the first 8 years of life. Am J Orthod Dentofacial Orthop 130: 31-36

9. Maguire JA (2000) The evaluation and treatment of pediatric oral habits. Dent Clin North Am 44: 659-669. 
Citation: Jyoti S, Pavanalakshmi GP (2014) Nutritive and Non-Nutritive Sucking Habits - Effect on the Developing Oro-Facial Complex; A Review. Dentistry 4: 203. doi:10.4172/2161-1122.1000203

Page 4 of 4

10. Schneider PE, Peterson J (1982) Oral habits: consideration in management. Pediatr clin North Am 29: 523-546.

11. Luzzi V, Guaragna M, lerardo G, Saccucci M, Consoli G, et al. Malocclusions and non-nutritive sucking habits: a preliminary study. Prog Orthod 12: 114-118.
12. Franco Varas V, Gorritxo Gil B (2011) Pacifier sucking habit and associated dental changes. Importance of early diagnosis. An Pediatr (Barc) 77: 374-380. 